\title{
Determinants of the length of stay in intensive care and in hospital after coronary artery surgery
}

\author{
J P Mounsey, M J Griffith, D W Heaviside, A Hedley Brown, D S Reid
}

\begin{abstract}
Background-Patients who have coronary artery surgery normally occupy intensive care beds for less than 24 hours. Longer stays may result in under use of cardiac surgical capacity. One approach to optimise surgical throughput is prospectively to identify fast track patients-that is, those who occupy an intensive care bed for less than 24 hours. A prospective audit of patients was performed to identify fast track patients by simple clinical criteria. Total length of hospital stay was also assessed in an attempt to predict which patients were likely to have a short postoperative stay, defined as $\leqslant 7$ days.
\end{abstract}

Methods-Baseline demographic details, cardiovascular risk factors, angiographic and operative details were recorded for 431 consecutive patients who underwent coronary surgery at a regional centre over a nine month period. Outcome measures were the duration of the stay in the intensive care unit in hours and total duration of the postoperative stay in hospital in days. In addition, two groups of patients who were thought to be fast track were identified prospectively. Fast track 1 patients were identified by criteria selected by cardiovascular physicians. These were age less than 60 years, stable angina, good left ventricular function (ejection fraction $>50 \%$ ), good renal function (serum creatinine $<120 \mu \mathrm{mol} / \mathrm{l}$ ), and no obesity, diabetes, or other serious disease. Fast track 2 patients were identified by criteria defined by cardiovascular surgeons. These were male sex, age less than 65 years, good left ventricular function and no peripheral vascular disease, diabetes, or other serious disease. The efficacy of both sets of criteria in predicting outcome was tested.

Results-344 (79.8\%) patients were fast track. Significant factors for the prediction of fast track patients by univariate analysis (with positive predictive accuracy and sensitivity) were left ventricular ejection fraction $>50 \%(83 \%, 80 \%)$, left ventricular end diastolic pressure $<13$ mm Hg (90\%, 59\%), creatinine less than $120 \mu \mathrm{mol} / 1$ (83\%, 87\%), and one or two vessel coronary disease $(89 \%, 34 \%)$. Of the patients categorised as fast track 1 $89 \%$ proved to be fast track (sensitivity $24 \%$ ), however, the fast track 2 characteristics were not significant. Age, sex, obesity, diabetes, hypertension, a history of obstructive pulmonary disease and unstable angina were not predictive of the duration of intensive care stay. Multivariate analysis indicated that only left ventricular end diastolic pressure and the number of diseased coronary arteries predicted fast track patients. These criteria separated patients into three groups. Those who were good risk had one or two vessel disease and left ventricular end diastolic pressure $<13$ $\mathrm{mm} \mathrm{Hg}$. They comprised $19 \%$ of the total and $93 \%$ of them were fast track. Those who were intermediate risk had either three vessel disease or left ventricular end diastolic pressure $>13 \mathrm{~mm} \mathrm{Hg}$ but not both. They comprised $49 \%$ of the total and $85 \%$ of them were fast track. Those who were poor risk had both three vessel disease and left ventricular end diastolic pressure $>13 \mathrm{~mm}$ Hg. They comprised $32 \%$ of the total and $62 \%$ of them were fast track. The $106(24 \%)$ patients who spent $\leqslant 7$ days in hospital after surgery were significantly younger (mean (SD) 55(8) v 58(8) years; $P<$ 0.001 ) with a lower incidence of previous myocardial infarction (positive predictive accuracy $30 \%$, sensitivity $53 \%$ ), were less likely to have a history of obstructive pulmonary disease $(25 \%, 98 \%)$, and more likely to have one or two vessel coronary disease $(33 \%, 41 \%)$. They were more likely to have an internal mammary artery as a bypass conduit (27\%, 89\%) and more likely to need fewer than three distal anastomoses of the vein graft $(29 \%$, $63 \%)$. By multivariate analysis only age was significantly predictive of hospital stay. Total hospital stay could not be satisfactorily modelled on the basis of the criteria tested here. Sex, obesity, diabetes, hypertension, unstable angina, renal function, and left ventricular function were not associated with hospital stay.

Conclusions-Most patients who had coronary artery surgery spent $\leqslant 24$ hours in intensive care, but most spent 
$>7$ days in hospital. The chance of a patient spending $\leqslant 24$ hours in intensive care could be predicted by the number of coronary arteries diseased and the left ventricular end diastolic pressure. Poor risk patients (32\%) had only a $62 \%$ chance of an intensive care unit stay of $\leqslant 24$ hours. A policy of scheduling no more than one such patient for surgery per day would be simple to institute and would maximise the use of surgical capacity.

(Br Heart f 1995;73:92-98)

Keywords: intensive care stay, coronary artery surgery, fast track.

The availability of intensive care beds often determines the throughput of patients who have cardiac surgery. Stays of $\leqslant 24$ hours on intensive care (fast track patients) free intensive care beds for the next day's routine operating list and allow optimum bed usage. Patients who have coronary artery surgery form the largest single cardiac surgical group. Most are fast track but a few require more than 24 hours intensive care. Identification of patients with the best chance of being fast track would allow throughput, at least in a proportion of beds, to be optimised. Conversely, identification of patients who are likely to need intensive care for more than 24 hours (slow track patients) would allow operations on these patients to be spread over the operating week thus minimising the chance of closure of the intensive care unit.

The need for conventional intensive care in the management of routine cardiac surgical patients has recently been questioned. ${ }^{12}$ Also the practice of designating a proportion of coronary surgery patients as fast track is gaining popularity. ${ }^{3}$ Both these practices would speed surgical throughput but it is difficult to identify suitable patients. Most are probably suitable but it would be helpful to identify suitable and unsuitable patients more confidently. Others have examined predictors of mortality in cardiac surgical procedures ${ }^{4-8}$ but there has been only one study of the factors affecting length of postoperative hospital stay. 9 Scoring systems that predict intensive care mortality have been developed ${ }^{1011}$ but not predictors of the duration of intensive care stay after cardiac surgery.

In an attempt to determine whether fast track patients could be identified by simple preoperative clinical criteria we prospectively surveyed all patients who underwent coronary artery bypass grafting in our unit over a 9 month period. We also assessed the total duration of postoperative hospital stay. Blockage of cardiac surgical ward beds is, in our experience, usually less of a problem than blockage of the intensive care unit. However, it would help us to plan our operating lists if we could identify those patients who are likely to need longer stays on the cardiac surgical ward.
Patients and methods

We prospectively studied 431 consecutive patients who underwent coronary surgery over a 9 month period (table 1). Data were collected from review of patient records and included baseline demographic details, details of cardiovascular risk factors, Canadian Cardiovascular Society angina grade ${ }^{12}$ and treadmill exercise tolerance, and the presence of serious coexistent disease. We obtained data on coronary angiography from patients' records. These included the number of major epicardial coronary arteries with significant obstructive disease ( $>70 \%$ stenosis), the presence of a left main stem stenosis (> $50 \%$ ), the left ventricular ejection fraction (calculated using standard computer software from the left ventricular cineangiogram, $30^{\circ}$ right anterior oblique projection), and left ventricular end diastolic pressure. Surgical details were obtained from the operation record including the urgency of surgical intervention, the number of distal anastomoses, and the nature of the bypass conduit. Twenty three $(5 \cdot 3 \%)$ of the cases were re-operations and there were no second or further re-operations.

For the purposes of analysis the following clinical variables were dichotomised prospectively: obesity (body mass index $\geqslant 30$ ); good or impaired renal function (creatinine $\leqslant 120$ $\mu \mathrm{mol} / /$ or $>120 \mu \mathrm{mol} / 1$; mild to moderate angina (grades 1 and 2); severe angina

Table 1 Baseline characteristics of 431 cononary surgery patients

\begin{tabular}{|c|c|}
\hline & No or $(S D)$ \\
\hline $\begin{array}{l}\text { Clinical characteristics: } \\
\text { Age (yr) } \\
\text { Sex male } \\
\text { Smoking } \\
\text { BMI > 30 } \\
\text { Diabetes } \\
\text { Hypertension } \\
\text { COAD } \\
\text { Creatinine > } 120 \mu \mathrm{mol} / 1 \\
\text { Angina grade } 3 \& 4 \\
\text { Bruce ETT < } 6 \text { min } \\
\text { Previous MI } \\
\text { Unstable angina }\end{array}$ & $\begin{array}{l}57 \cdot 4(8 \cdot 4) \\
84 \cdot 0 \% 362 \\
26 \cdot 5 \% 114 \\
12 \cdot 5 \% 54 \\
9 \cdot 5 \% 41 \\
20 \cdot 4 \% 88 \\
4 \cdot 9 \% 21 \\
16 \cdot 5 \% 71 \\
74 \cdot 7 \% 322 \\
74 \cdot 7 \% 322 \\
57 \cdot 3 \% 247 \\
29 \cdot 0 \% 125\end{array}$ \\
\hline $\begin{array}{l}\text { Angiographic characteristics: } \\
\text { Coros < } 3 \\
\text { LMS } \\
\text { LVEF (\%) } \\
\text { Good LVEF } \\
\text { LVEDP (mm Hg) } \\
\text { LOw LVEDP }\end{array}$ & $\begin{array}{l}31 \cdot 1 \% 134 \\
21 \cdot 1 \% 91 \\
59 \cdot 9(14 \cdot 2) \\
77 \cdot 2 \% 328 \\
14(7 \cdot 1) \\
53 \cdot 6 \% 162\end{array}$ \\
\hline $\begin{array}{l}\text { Operative details: } \\
\text { SVG } \geqslant 3 \\
\text { LIMA/RIMA } \\
\text { Bypass time (min) } \\
\text { Emergency } \\
\text { Previous operation }\end{array}$ & $\begin{array}{l}47 \cdot 1 \% 203 \\
80 \cdot 7 \% 348 \\
90 \cdot 425 \cdot 1 \\
37 \cdot 1 \% 160 \\
5 \cdot 3 \% 23\end{array}$ \\
\hline $\begin{array}{l}\text { Outcome: } \\
\text { ITU time (h) } \\
\text { ITU time }>72 \mathrm{~h} \\
\text { Hospital time (days) }\end{array}$ & $\begin{array}{l}43.6(81 \cdot 9) \\
10 \cdot 2 \% 44 \\
9 \cdot 6(8 \cdot 7)\end{array}$ \\
\hline $\begin{array}{l}\text { Mortality (\%): } \\
\text { On table } \\
\text { In hospital } \\
\text { Total } 30 \text { day }\end{array}$ & $\begin{array}{l}0.0021 \\
3.716 \\
4.921\end{array}$ \\
\hline
\end{tabular}

Angina grade, Canadian Cardiovascular Society angina grade; BMI, body mass index; Bruce ETT, Bruce protocol exercise tolerance; Bypass time, time spent on cardiopulmonary bypass; COAD, history of asthma or chronic obstructive pulmonary disease; Coros, number of epicardial coronary arteries diseased; Good LVEF, LVEF > 50\%; LIMA/RIMA, use of right and/or left internal mammary artery as a bypass conduit LMS, left main stem stenosis; low LVEDP, LVEDP < 13 mmHg; LVEDP, left ventricular end diastoloc pressure LVEF, left ventricular ejection fraction; MI, myocardial infarction; SVG, number of saphenous vein graft distal anastomoses. 
(grades 3 and 4); good exercise tolerance (Bruce protocol exercise time $>6$ minutes); and poor exercise tolerance (Bruce protocol exercise tolerance $\leqslant 6$ minutes, including patients unable to attempt an exercise test because they had unstable angina. The prospectively defined angiographic variables included good (ejection fraction $\geqslant 50 \%$ ) and poor $(<50 \%)$ left ventricular function; low ( $\leqslant 13 \mathrm{~mm} \mathrm{Hg})$ and high $(>13 \mathrm{~mm} \mathrm{Hg})$ left ventricular end diastolic pressure; three vessel coronary disease; and one and two vessel coronary disease. The prospectively defined surgical variables were the number of saphenous vein graft distal anastomoses $(<3$ $v \geqslant 3$ ), the use of either or both internal mammary arteries as a bypass conduit or no internal mammary artery; and the urgency of the surgical intervention as elective (waiting list) cases or urgent cases. Urgent cases were further subdivided into those requiring surgery within 24 hours of admission (including patients with intra-aortic balloon pumps in situ) and those requiring surgery during the current admission.

Duration of stay on the intensive care ward was obtained from the ward diary. Fast track status was defined as discharge from the intensive care unit $\leqslant 24$ hours after admission. The remaining patients were defined as slow track. Duration of stay for patients spending $>24$ but $<72$ hours on intensive care was expressed to the nearest 12 hours. For patients spending $>72$ hours on intensive care the length of stay was expressed in multiples of 24 hours. Duration of hospital stay, expressed as days after surgery, and 30 day mortality were obtained from the hospital events database. Short stay patients were defined as those spending $\leqslant 7$ days in hospital after surgery; other patients were defined as long stay.

Potential fast track patients were identified prospectively according to two sets of criteria. The first set of criteria; fast track 1 , defined

Table 2 Characteristics of 431 coronary surgery patients by duration of stay on ITU

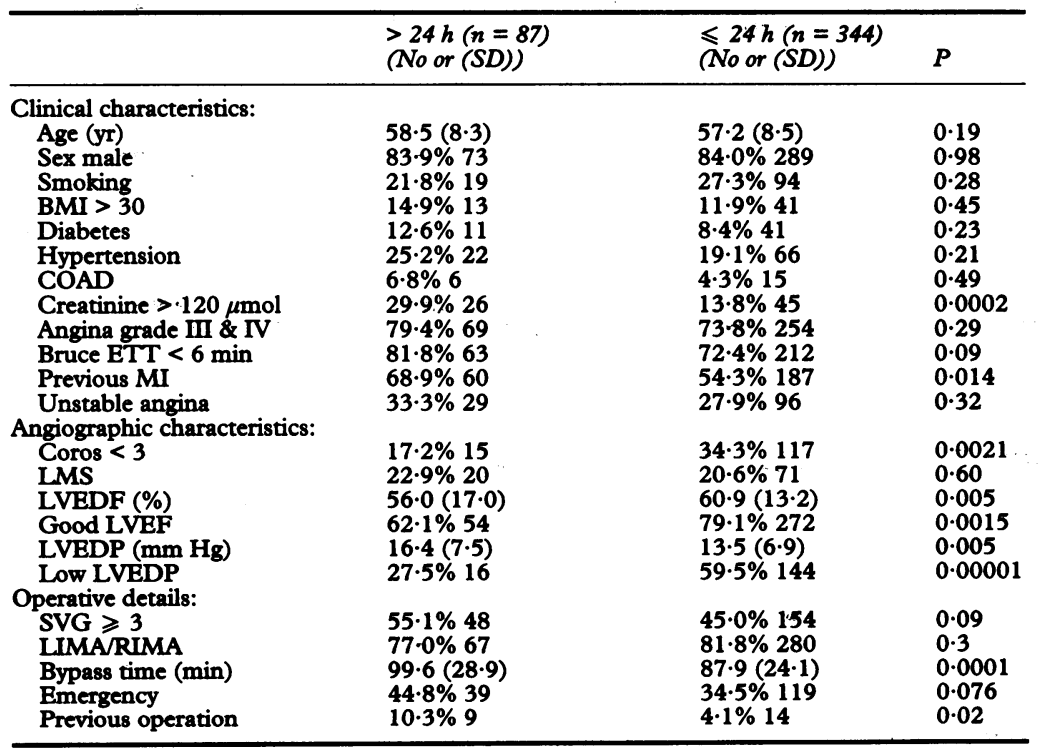

See footnote to table 1 for abbreviations by cardiovascular physicians, was stable angina; age $<60$, good left ventricular function (left ventricular ejection fraction $>50 \%$ ); good renal function (creatinine $<120 \mu \mathrm{mol} / \mathrm{l}$ ); and the absence of obesity (body mass index greater than 30 ), diabetes, or other serious disease. The second set, fast track 2, defined by cardiac surgeons, was male sex, age < 65 years; stable angina; good left ventricular function (left ventricular ejection fraction $>50 \%$ ); and the absence of diabetes; peripheral vascular disease or other serious disease. Renal function was not specified beyond the absence of a need for dialysis. The physicians and surgeons were unaware that the other was being canvassed. Potential fast track patients were treated in exactly the same way as the remainder of the group and the efficacy of the criteria in predicting an intensive care stay of $\leqslant 24$ hours was assessed.

\section{STATISTICAL ANALYSIS}

Statistical analysis was performed with the SPSS/PC. Continuous variables were analysed by $t$ tests. Dichotomised variables were analysed by the $\chi^{2}$ test. Stepwise logistic discriminant analysis was used for GLIM. ${ }^{13}$

\section{Results}

INDIVIDUAL PREDICTORS OF FAST TRACK

STATUS

Table 2 shows the characteristics of all coronary surgery patients according to fast track status. Overall $344 / 431(79.8 \%)$ of patients spent $\leqslant 24$ hours on intensive care-that is; were fast track-and 44/431 (10.2\%) of patients spent $>72$ hours on intensive care. The only clinical characteristics significantly associated with being a fast track case were the absence of previous myocardial infarction and good renal function. Age, sex, body mass index, obesity, diabetes, hypertension, a history of obstructive pulmonary disease, angina grade, exercise tolerance, and unstable angina were not significantly associated with time spent on the intensive care unit.

The time spent in the intensive care ward was significantly associated with left ventricular function as assessed by left ventricular ejection fraction and left ventricular end diastolic pressure. Left ventricular ejection fraction was significantly higher and left ventricular end diastolic pressure was significantly lower in fast track patients. The association with left ventricular function was also reflected by a significantly higher proportion of fast track patients who had a left ventricular ejection fraction $>50 \%$ and left ventricular end diastolic pressure $<13 \mathrm{~mm} \mathrm{Hg}$. One or two vessel coronary disease was significantly predictive of fast track status but left main stem stenosis was not associated with time on the intensive care ward.

Fast track patients spent significantly less time on cardiopulmonary bypass. This was not associated with a significantly smaller number of distal vein graft anastomoses or with a greater use of internal mammary 
Table 3 Positive predictive accuracy and sensitivity of significant factors in prediction of fast track status and a short stay in hospital and positive predictive accuracy and sensitivity of different fast tract characteristics

\begin{tabular}{lll}
\hline & $\begin{array}{l}\text { Positive predictive } \\
\text { accuracy (\%) }\end{array}$ & Sensitivity (\%) \\
\hline Fast track status (<24 h in ITU): & & \\
Good LV function (LVEF > 50\%) & 83 & 80 \\
Low LVEDP (LVEDP < 13 mm Hg) & 90 & 59 \\
1 or 2 vessel disease & 89 & 34 \\
Good renal function (creatinine < 120 $\mu \mathrm{mol} / \mathrm{l})$ & 83 & 87 \\
Short stay in hospital (< 6 days): & 30 & 53 \\
No history MI & 25 & 98 \\
No history COAD & 33 & 63 \\
1 or 2 vessel disease & 29 & 89 \\
< 3 SVG & 27 & 24 \\
LIMARIMA & 89 & 35 \\
Fast track characteristics: & 80 & \\
Fast track 1 & & \\
Fast track 2 &
\end{tabular}

See footnote to table 1 for abbreviations.

arteries as the bypass conduit in the fast track group, although there was a non-significant trend in this direction for both variables. Bypass time was significantly longer in patients operated on by consultants than in patients operated upon by those in sub-consultant grades (93 (25) minutes $v 85$ (24) minutes (mean (SD), $\mathrm{P}=\mathbf{0} \cdot 001$ ).

There was a trend towards an association between emergency surgery and slow track status; this did not reach statistical significance. This trend was not associated with a preponderance of unstable angina in the group that was not fast track (see above). Eight patients required surgery within 24 hours of admission and three of these had intra-aortic balloon pumps in situ. All were first operations and all survived. The three patients with balloon pumps in situ were slow track; the other five patients were fast track. Patients undergoing repeat surgery were significantly more likely to be slow track.

Table 3 shows the positive predictive accuracy and sensitivity of the factors significantly associated with fast track status. The factors with the highest predictive accuracy were low

Table 4 Characteristics of 431 coronary surgery patients by duration of stay on hospital

\begin{tabular}{|c|c|c|c|}
\hline & $\begin{array}{l}\leqslant 7 \text { days }(n=106) \\
(\text { No or }(S D))\end{array}$ & $\begin{array}{l}>7 \text { days }(n=325) \\
(\text { No or }(S D))\end{array}$ & $P$ \\
\hline $\begin{array}{l}\text { Age (yr) } \\
\text { Sex (male) } \\
\text { Smoking } \\
\text { BMI > 30 } \\
\text { Diabetes } \\
\text { Hypertension } \\
\text { COAD } \\
\text { Creatinine > } 120 \mu \mathrm{mol} \\
\text { Angina grade III \& IV } \\
\text { Bruce ETT < } 6 \text { min } \\
\text { Previous MI } \\
\text { Unstable angina }\end{array}$ & $\begin{array}{c}55 \cdot 1(8 \cdot 9) \\
88 \cdot 6 \% 94 \\
25 \cdot 5 \% 27 \\
8 \cdot 5 \% 9 \\
9 \cdot 5 \% 10 \\
16 \cdot 0 \% 17 \\
0.9 \% 1 \\
10 \cdot 4 \% 11 \\
66 \cdot 0 \% 70 \\
71 \cdot 0 \% 71 \\
47 \cdot 2 \% 50 \\
21 \cdot 7 \% 23\end{array}$ & $\begin{array}{l}58 \cdot 1(8 \cdot 1) \\
82 \cdot 5 \% 268 \\
26 \cdot 7 \% 87 \\
14 \cdot 1 \% 46 \\
9 \cdot 2 \% 30 \\
21 \cdot 8 \% 71 \\
6 \cdot 1 \% 20 \\
18 \cdot 2 \% 59 \\
77 \cdot 8 \% 253 \\
75 \cdot 2 \% 204 \\
60 \cdot 9 \% 198 \\
31 \cdot 4 \% 102\end{array}$ & $\begin{array}{l}0.001 \\
0.12 \\
0.78 \\
0.13 \\
0.95 \\
0.20 \\
0.048 \\
0.061 \\
0.017 \\
0.48 \\
0.014 \\
0.056\end{array}$ \\
\hline $\begin{array}{l}\text { Angiographic characteristics: } \\
\text { Coros < } 3 \\
\text { LMS } \\
\text { LVEDF (\%) } \\
\text { Good LVEF } \\
\text { LVEDP (mm Hg) } \\
\text { Low LVEDP }\end{array}$ & $\begin{array}{l}40 \cdot 9 \% 43 \\
21 \cdot 7 \% 23 \\
61 \cdot 1(14 \cdot 3) \\
80 \cdot 0 \% 84 \\
14 \cdot 7(7 \cdot 1) \\
46 \cdot 1 \% 35\end{array}$ & $\begin{array}{l}27 \cdot 5 \% 89 \\
20 \cdot 9 \% 68 \\
59 \cdot 5(14 \cdot 2) \\
74 \cdot 5 \% 242 \\
13 \cdot 7(7 \cdot 1) \\
56 \cdot 3 \% 224\end{array}$ & $\begin{array}{l}0.009 \\
0 \cdot 83 \\
0 \cdot 31 \\
0 \cdot 41 \\
0 \cdot 29 \\
0 \cdot 12\end{array}$ \\
\hline $\begin{array}{l}\text { Operative details: } \\
\text { SVG } \geqslant 3 \\
\text { LIMA/RIMA } \\
\text { Bypass time (min) } \\
\text { Emergency } \\
\text { Previous operation }\end{array}$ & $\begin{array}{l}37 \cdot 1 \% 39 \\
88 \cdot 5 \% 93 \\
81 \cdot 8(27 \cdot 1) \\
31 \cdot 1 \% 33 \\
5 \cdot 7 \% 6\end{array}$ & $\begin{array}{c}50 \cdot 5 \% 164 \\
78 \cdot 7 \% 256 \\
92 \cdot 8(24 \cdot 4) \\
38 \cdot 5 \% 125 \\
5 \cdot 2 \% 17\end{array}$ & $\begin{array}{l}0.018 \\
0.026 \\
0.0001 \\
0 \cdot 18 \\
0.85\end{array}$ \\
\hline
\end{tabular}

See footnote to table 1 for abbreviations. left ventricular end diastolic pressure $(90 \%)$ and one or two vessel disease $(89 \%)$. The most sensitive factors were good left ventricular function (80\%) and good renal function (87\%).

Fast track patients had a significantly shorter mean postoperative hospital stay $(8 \cdot 1$ (3.5) days $v 15.6 \pm 16.8$ days, $\mathrm{P}<0.0001$ ) although the difference between the two groups was magnified somewhat by patients who died early ( 24 hours or less) after surgery (see below for further discussion of this point).

INDIVIDUAL PREDICTORS OF A SHORT STAY IN HOSPITAL

Table 4 shows the characteristics of all the patients by duration of stay in hospital. Short stay patients were significantly younger and were less likely to have a history of obstructive pulmonary disease. They had a lower incidence of previous myocardial infarction. Unlike the length of stay in the intensive care ward this latter factor was not reflected in a significant trend in left ventricular function, however assessed. Also in contrast to intensive care time, there was a significant association between mild to moderate angina and a short stay in hospital. There was a trend towards an association between unstable angina and poor renal function, and a long stay in hospital which was of borderline significance for each variable. Sex, smoking habit, body mass index, obesity, diabetes, hypertension, and exercise tolerance were not associated with duration of hospital stay.

Short stay patients were significantly more likely to have one or two vessel coronary disease. There was a similar (presumably related) significant trend in the number of distal vein graft anastomoses, in the use of an internal mammary artery as a bypass conduit, and in time spent on cardiopulmonary bypass. Short stay patients were more likely to have received $<3$ saphenous vein grafts and an internal mammary artery, and had a shorter time on bypass. The presence of a left main stem stenosis was not related to length of hospital stay.

Somewhat surprisingly reoperation was not related to hospital stay. This is in contrast to intensive care time (see above): but because the numbers were small both these results should be interpreted with caution. Neither emergency nor elective operation was significantly related to length of hospital stay.

The positive predictive accuracy and sensitivity for the factors that were of significance in predicting hospital stay are listed in table 3. No factor was of sufficient predictive value to be of use in planning hospital bed usage and only absence of obstructive pulmonary disease and the use of an internal mammary artery as a bypass conduit was of useful sensitivity.

Most short stay patients spent $\leqslant 24$ hours on the intensive care unit $(90.6 \%$ compared with $76.3 \%$ of long stay patients, $P=0.017$ ). This group contains several patients who died early after surgery. 
MORTALITY STATISTICS

Twenty one $(4.9 \%)$ patients died within 30 days of surgery (table 1). Most deaths occurred in hospital (17/21) and there was one death on the operating table. Ten of the 17 hospital deaths occurred on the intensive care unit. Six of these died within 24 hours of entering intensive care and were therefore classified as fast track. The other four stayed on the intensive care unit for 48 to 816 hours (mean 222 hours). The six patients who died in hospital after leaving intensive care had stays ranging from 48 to 816 hours (mean 348 hours) and spent a total of 14-77 (mean 35) days in hospital. Four patients died after leaving hospital. Two of these were fast track and the other two spent 48 and 312 hours in intensive care. Hospital stay ranged from 6 to 21 days.

Overall nine patients who died were fast track in that they died on the operating table, early on intensive care, or left intensive care within 24 hours and died later. Eleven patients spent $\leqslant 7$ days in hospital and of these nine died on the intensive care ward and one died on the operating table.

The number of deaths was small so it is difficult to draw meaningful predictive statistical associations. However, patients who died had significantly poorer left ventricle function (left ventricular ejection fraction $51(21) \% v$ 60 (14)\% (mean (SD)), P=0.003). There was no association between unstable angina or emergency surgery and mortality.

\section{PREDICTIVE VALUE OF FAST TRACK CRITERIA} Fast track patients were a prospectively defined subset of the coronary surgery population who were thought likely to have a high probability of spending $\leqslant 24$ hours on the intensive care unit. Two sets of criteria were tested.

Fast track 1 criteria predicted that 92 $(21 \%)$ of patients would be fast track. The positive predictive accuracy of these criteria was $89 \%(P=0.016)$. Sensitivity was, however, only $24 \%$ because many patients who were not predicted to be fast track spent $<24$ hours on the intensive care unit. Five $(5 \cdot 4 \%)$ fast track 1 patients spent more than 72 hours on the intensive care unit. Only one fast track 1 patient died.

Fast track 2 criteria predicted that 149 $(35 \%)$ of patients would be fast track. The positive predictive accuracy of fast track 2 criteria was $80 \%$ and sensitivity was $35 \%$ (table 3) and neither of these was significantly better than chance in predicting fast track status. Five (3.4\%) of fast track 2 patients died.

Table 5 Modelled and actual proportions of fast track patients based on the LVEDP and the number of diseased coronary arteries

\begin{tabular}{|c|c|c|c|c|c|}
\hline \multirow{2}{*}{$\begin{array}{l}\text { Low LVEDP } \\
(<13 \mathrm{~mm} \mathrm{Hg})\end{array}$} & \multirow{2}{*}{$\begin{array}{l}\text { No of } \\
\text { arteries }\end{array}$} & \multirow[b]{2}{*}{$\%$ of groups } & \multicolumn{2}{|c|}{ Fast track patients (\%) } & \multirow[b]{2}{*}{ Risk } \\
\hline & & & Modelled & Actual & \\
\hline $\begin{array}{l}\text { Yes } \\
\text { No } \\
\text { Yes } \\
\text { No }\end{array}$ & $\begin{array}{l}<3 \\
<3 \\
3 \\
3\end{array}$ & $\begin{array}{l}19 \\
15 \\
34 \\
32\end{array}$ & $\begin{array}{l}94 \\
82 \\
86 \\
62\end{array}$ & $\begin{array}{l}92 \\
86 \\
88 \\
61\end{array}$ & $\begin{array}{l}\text { Good } \\
\text { Intermediate } \\
\text { Intermediate } \\
\text { Poor }\end{array}$ \\
\hline
\end{tabular}

See footnote to table 1 for abbreviations.
MULTIVARIATE ANALYSIS

By univariate analysis the most significant predictors of fast track status were good left ventricular function as assessed by both left ventricular ejection fraction and left ventricular end diastolic pressure, good renal function, the number of coronaries diseased, and time spent on cardiopulmonary bypass. Of the variables available preoperatively, only the left ventricular end diastolic pressure and the number of coronaries diseased were required to predict fast track status by stepwise logistic discriminant analysis (residual deviance 19.87 on 12 degrees of freedom). Table 5 shows the modelled and actual proportions of fast track patients based on a simplified model incorporating these two risk factors. Ninety two percent of patients with 1 or 2 vessel disease and a low left ventricular end diastolic pressure (< $13 \mathrm{~mm} \mathrm{Hg}$ ) were fast track compared with $61 \%$ of patients with three vessel disease and a poor left ventricular end diastolic pressure. Taking the mean of modelled and actual proportions, patients with one or two vessel disease and a low left ventricular end diastolic pressure had a $93 \%$ chance of being fast track (good risk patients), those with either 3 vessel disease or a poor left ventricular end diastolic pressure (intermediate-risk patients) had an $85 \%$ chance of being fast track, and those with both three vessel disease and a poor left ventricular end diastolic pressure (poor risk patients) had only a $62 \%$ chance of being fast track. There were $19 \%, 49 \%$, and $32 \%$ good, intermediate and poor risk patients respectively in the group.

Only age and cardiopulmonary bypass time were significant predictors of a short stay in hospital ( $\leqslant 7$ days) by multivariate analysis. Modelling of hospital stay was not attempted.

\section{Discussion}

In recent years there has been considerable interest in optimising throughput of cardiac surgery patients to make the most efficient use of limited resources. Most cardiac surgery patients will spend some time in intensive care or an equivalent nursing unit so the factors affecting the duration of this part of the hospital stay have clear planning implications. It is especially important in planning day to day operating schedules because if all the intensive care beds are blocked, operating lists may be cancelled and theatre staff underemployed.

In some units patients are nursed in specialised high dependency areas in the immediate postoperative phase. ${ }^{12}$ These units, while retaining many of the features of an intensive care unit, have the advantage of a lower nurse/patient ratio and therefore (presumably) lower cost. The differences between these units and the dedicated cardiac intensive care area as detailed in this report are subtle. Intensive care beds as described here are not general intensive care beds, and cardiac surgical patients do not compete for beds with critically ill general medical patients. Reports emanating from the high dependency 
units have emphasised modifications of surgical and anaesthetic practice including use of minimum hypothermia and early extubation. Certainly these practices seem to hasten transfer to general wards, and surgical high dependency areas are safe and effective for most patients. Previous reports of surgical high dependency units operated some form of patient selection-based on disease severity and patient condition-but neither formalised their selection criteria. In our patients we did not assess the effects of early extubation or patient temperature on entry to intensive care. We think it likely, however, that the risk groups we defined, based as they are on simple variables, are likely to be as applicable in high dependency units as they are after traditional hypothermic bypass. High risk patients as we define them are likely to be those at highest risk of a poor outcome in a high dependency setting.

\section{PREDICTORS OF FAST TRACK STATUS}

Overall nearly $80 \%$ of this unselected series of patients spent $\leqslant 24$ hours on intensive careindicating that coronary surgery patients as a group have a high chance of being fast track. This compares with a fast track rate of $93.4 \%$ among selected patients in a centre operating a high dependency unit. ${ }^{1}$ By univariate analysis, factors that were significantly better than chance in predicting fast track status were good renal function, good left ventricular function, one or two vessel coronary disease, and time spent on cardiopulmonary bypass. Among the potential measures of left ventricular function, left ventricular end diastolic pressure was most closely associated with fast track status.

Of the two groups of patients identified prospectively who were thought likely to be fast track, only fast track 1 was significantly predictive of fast track status. The two sets of criteria were similar apart from the stipulation of good renal function in the fast track 1 group, which emphasises the importance of renal function in predicting the duration of stay in intensive care. Morbidity and mortality are well known to be increased in patients with end stage renal failure requiring dialysis, and those with functioning renal transplants. ${ }^{14}$ These patients have complex metabolic derangements and often also multiple medical problems. It is unlikely that any metabolic derangement associated with the modest elevations of creatinine observed in most patients with "poor renal function" in this study was sufficient to explain the increased duration of stay on intensive care. It seems more likely that impaired renal function was a marker for multiple system failure and a patient at overall poor risk.

Previous attempts at risk stratification in coronary surgery have focused mainly on identification of the risk of peri-procedural death. Parsonnet et al noted that old age, female gender, diabetes, renal dialysis, emergency surgery, re-operation, poor left ventricular function, and preoperative catastrophic states, including intra-aortic balloon pump- ing, were associated with a high risk of operative mortality. ${ }^{4}$ Others have also emphasised the importance of older age, emergency surgery, severe and diffuse coronary disease, and poor left ventricular function in the prediction of operative mortality. ${ }^{5-8}$ Munoz et al studied predictors of the cost of hospital admission and found that intensive care usage (length of stay was not specified), treatment with blood or plasma, and emergency admission were associated with higher than average costs and a prolonged hospital stay. ${ }^{15}$

When we planned this study it was thought likely that fast track status would be governed by risk factors similar to those predictive of death - and both sets of prospectively defined fast track characteristics included criteria similar to those noted above. In the event the fast track characteristics were poor predictors of intensive care stay and only the simple physiological variables-left ventricular function and renal function-and the number of coronaries diseased were significantly predictive. Other characteristics associated with high operative mortality, and traditionally thought to epitomise long stay intensive care patients-for example old age, obesity, diabetes, and unstable angina-were not in themselves associated with the duration of stay in intensive care.

The model derived from multivariate analysis separated patients into good, intermediate, and poor risk on the basis of the number of coronaries diseased and the left ventricular end diastolic pressure. Overall, $68 \%$ of patients were good or intermediate risk, with at least an $85 \%$ chance of fast track status. The remaining $32 \%$ of patients were poor risk, with only a $62 \%$ chance of fast track status. This model suggests two policies that would minimise bed blockage in the intensive care unit-selection of exclusively good risk patients for a proportion of beds and avoidance of operating on more than one poor risk patient a day. Either policy would be simple to institute but the latter would have a greater impact on bed blockage. This is because poor risk patients make up a higher proportion of the cohort than good risk patients and those patients are most likely to block intensive care unit beds. If there are about 250 routine operating days/year, then for our case mix (and assuming, as seems reasonable, a large pool of potential surgical candidates), a throughput of more than the 800 coronary surgery patients who pass through this unit per year would be required to make it necessary to operate on more than one poor risk patient a day. Alternatively, since routine cardiac surgery is performed over a five day week, if poor risk patients had surgery towards the end of the week, then the extra time they would be likely to spend on the intensive care unit would be at the weekend-when the intensive care unit tends to be quieter.

PREDICTORS OF A SHORT STAY IN HOSPITAL

Several factors were weakly predictive of a short stay in hospital ( $\leqslant 7$ days) by univariate 
analysis but by stepwise logistic regression only age and time spent on cardiopulmonary bypass were significant. These findings are in accord with those of Weintraub et al ${ }^{9}$ who showed significant associations of age, angina grade, previous myocardial infarction, and the use of an internal mammary artery with a short stay in hospital, similar to those reported here. However, in contrast to the population reported here, Weintraub et al showed that elective surgery and good left ventricular function were predictive of a short hospital stay.

The relation between patient age and total hospital stay in our population is too approximate a guideline to be of practical value in planning. The influence of age may reflect the importance of less easily quantifiable variables such as social circumstances, mobility, or other non-cardiac disease in the highly complex relation that governs total hospital stay.

\section{CARDIOPULMONARY BYPASS TIME}

Time spent on cardiopulmonary bypass cannot be predicted in advance and is therefore not of value in assessing the risk of a long stay on intensive care or a long stay in hospital. Bypass time may reflect the technical difficulty of the operative procedure or the technical skill of the operator. The observation that bypass time was significantly longer in patients operated upon by consultants compared with other grades suggests that the skill of the operator is likely to be of less significance than the technical difficulty of the case. The lack of a relation between the number of distal anastomoses of the saphenous vein graft and intensive care stay suggests that factors other than the amount of surgery required determined the technical difficulty of the case.

Chaos theory indicates that, in complex biological systems, predictability is the exception rather than the rule. ${ }^{16}$ The inability to predict with complete confidence the duration of intensive care or total hospital stay after cardiac surgery is likely to be intrinsic to the system rather than a consequence of inadequate knowledge about it. Weintraub et al noted that an abnormally long hospital stay (and by inference also a long stay on the intensive care unit) was most often the result of uncommon but severe complications such as perioperative myocardial infarction, strokes, and wound infection. ${ }^{9}$ These events are not predictable from clinical or angiographic variables and therefore an element of unpredictability is inevitable. The data presented here indicate that although most $(80 \%)$ of coronary surgery patients are fast track, groups can be identified with significantly better or poorer risk of fast track status. Application of our criteria should minimise random bed blockage in the intensive care unit and maximise throughput, although some patients will inevitably continue to suffer unpredictable perioperative complications. It would be of interest to test the criteria in a second cohort of patients managed in an intensive care unit and also to test the applicability of the criteria predicting a poor outcome in high dependency units.

In conclusion, as expected most $(80 \%)$ of coronary surgery patients spent $\leqslant 24$ hours in intensive care. Patients could be separated into good or poor risk of being fast track on the basis of the number of diseased coronaries and the left ventricular end diastolic pressure. Patients with one or two vessel coronary disease and a low left ventricular end diastolic pressure had a $93 \%$ chance of fast track status compared with a $62 \%$ chance for patients with three vessel coronary disease and a high left ventricular end diastolic pressure. These poor risk patients represented only $32 \%$ of the group and given our current workload we could schedule only one such patient for surgery each working day. This policy would reduce bed blockage in the intensive care unit.

We acknowledge the assistance of Dr D Appleton of the Department of Medical Statistics, Newcastle University, with the statistical analyses in this paper.

1 Jindani A, Aps C, Neville E, Somnez B, Tun K, Williams BT. Postoperative cardiac surgical care: an alternative approach. Br Hear $\mathcal{F}$ 1993;69:59-64.

2 Westaby S, Pillai R, Parry A, O'Regan D, Giannopoulos N, Grebenik K, Sinclair M, Fisher A. Does modern cardiac surgery require conventional intensive care. Eur $\mathcal{F}$ Cardiothorac Surg 1993;7:313-18.

3 Cotton P. Fast track improves CABG outcomes. $¥ A M A$ 1993;270:2023.

4 Parsonnet V, Dean D, Bernstein AD. A Method of uniform stratification of risk for evaluating the results of surgery in acquired adult heart disease. Circulation 1989;79(suppl I)I.3-I.12.

5 Wright JW, Pifarre R, Sullivan HJ, Montoya A, Bakhos $\mathrm{M}$, Grieco J, et al. Multivariate Discriminant analysis of risk factors for operative mortality following isolated risk factors for operative mortality following is

6 Edwards FH, Albus RA, Zajtchuk R, Graeber GM, Barry MJ, Rumisek JD, Arishita G. Use of a Bayesian statistiMJ, Rumisek JD, Arishita G. Use of a Bayesian statisti-
cal model for risk assessment in coronary artery surgery. cal model for risk assessment in co

7 Teoh KH, Christakis GT, Weisel RD, Katz AM, Tong KP, Mickleborough LL, et al. Increased risk of urgent revascularization. If Thorac Cardiovasc Surg 1987;93: 291-9.

8 Kennedy JW, Kaiser GC, Fisher LD, et al. Multivariate discriminant analysis of the clinical and angiographic predictors of operative mortality from the Collaborative Study in Coronary Artery Surgery. $\mathcal{F}$ Thorac Cardiovasc Surg 1980;80:867-76.

9 Weintraub WS, Jones EL, Craver J, Guyton R, Cohen C. Determinants of prolonged length of hospital stay after coronary bypass surgery. Circulation 1989;80:276-84

10 Knaus WA, Draper EA, Wagner DP, Zimmerman JE. APACHE II: A severity of disease classification. Crit Care Med 1985;13:818-29.

11 Knaus WA, Draper EA, Wagner DP, Zimmerman JE. An evaluation of outcome from intensive care in major medical centers. Ann Intern Med 1986;104:410-18.

12 Campeau L. Grading of angina pectoris (letter). Circulation 1975;54:522-3.

13 Baker RJ, Nelder JA. The GLIM system (Release 3) manual. Numerical algorithms group for the Royal ual. Numerical algorithms group

14 Monson BK, Wickstrom PH, Haglin J, Francis G, Comty $\mathrm{CM}$, Helseth HK. Cardiac operations and end stage CM, Helseth HK. Cardiac operations and end

15 Munoz E, Luber J, Ratner L, Goldstein J, Margolis I, Munoz E, Luber J, Ratner L, Goldstein J, Margolis I,
Wise L. The identifier concept: Variables to stratify patient costs within cardiothoracic surgical diagnostic related groups. F Thorac Cardiovasc Surg 1988;96: 376-81

16 Firth WJ. Chaos-Predicting the unpredictable. $B M F$ 1991;303:1565-8. 